Abstract-Stable isotope (SI) values of carbon $\left(\delta^{13} \mathrm{C}\right)$ and nitrogen $\left(\delta^{15} \mathrm{~N}\right)$ are useful for determining the trophic connectivity between species within an ecosystem, but interpretation of these data involves important assumptions about sources of intrapopulation variability. We compared intrapopulation variability in $\delta^{13} \mathrm{C}$ and $\delta^{15} \mathrm{~N}$ for an estuarine omnivore, Spotted Seatrout (Cynoscion nebulosus), to test assumptions and assess the utility of SI analysis for delineation of the connectivity of this species with other species in estuarine food webs. Both $\delta^{13} \mathrm{C}$ and $\delta^{15} \mathrm{~N}$ values showed patterns of enrichment in fish caught from coastal to offshore sites and as a function of fish size. Results for $\delta^{13} \mathrm{C}$ were consistent in liver and muscle tissue, but liver $\delta^{15} \mathrm{~N}$ showed a negative bias when compared with muscle that increased with absolute $\delta^{15} \mathrm{~N}$ value. Natural variability in both isotopes was 5-10 times higher than that observed in laboratory populations, indicating that environmentally driven intrapopulation variability is detectable particularly after individual bias is removed through sample pooling. These results corroborate the utility of SI analysis for examination of the position of Spotted Seatrout in an estuarine food web. On the basis of these results, we conclude that interpretation of SI data in fishes should account for measurable and ecologically relevant intrapopulation variability for each species and system on a case by case basis.

Manuscript submitted 17 January 2012. Manuscript accepted 4 January 2013. Fish. Bull. 111:111-121 (2013). doi:10.7755/FB.111.2.1

The views and opinions expressed or implied in this article are those of the author (or authors) and do not necessarily reflect the position of the National Marine Fisheries Service, NOAA.

\title{
Quantifying intrapopulation variability in stable isotope data for Spotted Seatrout (Cynoscion nebulosus)
}

\author{
Richard S. Fulford (contact author) \\ Kevin Dillon \\ Email address for contact author: fulford.richard@epa.gov \\ Department of Coastal Sciences \\ University of Southern Mississippi \\ Gulf Coast Research Laboratory \\ 703 East Beach Road \\ Ocean Springs, Mississippi 39564
}

The mandate for management of fisheries has shifted toward a focus on ecosystem-based fisheries management (EFM) (Brodziak and Link, 2002). The EFM approach differs from historical single-species management in that EFM acknowledges the linkages between ecosystem components as well as the spatial and temporal variability in those linkages (Arkema et al., 2006; Christensen et al., 1996; NRC 1999; Thomas and Huke, 1996). The EFM paradigm has great potential to improve the ability of managers to accurately predict and appropriately respond to the impacts of multiple stressors on exploited fish populations. However, the data needs of EFM are high, and the acquisition of these data has generally lagged behind development of EFM theory (Dame and Christian, 2006).

Quantification of trophic connections among species is an important precursor for the shift to EFM because such data support the development of food-web network models that allow fishing pressure to be analyzed in an ecological context with other sources of mortality (Christensen and Pauly, 2004). Quantitative techniques, like stable isotope (SI) analysis, have been widely applied to fish populations as a method for quantification of the trophic links between predator and prey (Power et al., 2002; Rooker et al., 2006). Stable isotope data are well suited to the development of network models of food webs because they are timeintegrated and provide data on the relative importance of entire trophic pathways down to sources of primary production (Peterson and Fry, 1987). Yet, the interpretation of stable isotope data requires several important assumptions, and these assumptions should be carefully analyzed if results may affect management decision making.

Key assumptions made in interpreting stable isotope data involve the sources of variability in isotopic values for a given population (Peterson and Fry, 1987). Population variability integrates several sources of variability, including environmental influences (Barnes et al., 2008), differences in individual behavior (Sweeting et al., 2005), ontogeny, growth, and tissue turnover rates (Herzka, 2005; Perga and Gerdeaux, 2005), and prey availability and feeding success (Sweeting et al., 2005). Partitioning out these sources of variability, particularly for an omnivorous consumer in an estuarine ecosystem, can be complex. In particular, quantification of intrapopulation variability in isotope data (e.g., variability due to differences in individual behavior or tissue turnover rates) is important for separating this variability from changes that are ecologically important (e.g., changes due to ontogeny or the environment). 
Intrapopulation variability in SI compositions can be particularly difficult to interpret in species and ecosystems with multiple overlapping trophic pathways. Omnivorous fish species, such as Eurasian Perch (Perca fluviatilis) and Spotted Seatrout (Cynoscion nebulosus), hold important positions in aquatic food webs as trophic mediators of primary production, but they have complex stable isotope signatures that require a close examination of assumptions regarding intrapopulation variability (Quan et al., 2007; Quevedo et al., 2009). The estuarine habitat of Spotted Seatrout, in particular, is highly complex; it contains both potential aquatic sources (e.g., phytoplankton, microphytobenthos, submerged aquatic vegetation, marsh macrophytes) and terrestrial sources of primary production that can vary in importance for estuarine food webs, both temporally and spatially. One of the key questions with the food-web approach to EFM that can be addressed with stable isotope data is an estimation of the relative importance of different sources of organic matter for the production of estuarine consumers. Yet, individual fishes exposed to the same suite of prey resources may have very different isotopic values, and that variation may overemphasize the importance of omnivory and confound detection of any population-level differences in isotope ratios (Zanden et al., 2010). The utility of stable isotope data for analysis of estuarine ecosystems will be greatly enhanced when sources of uncertainty have been well-quantified for important populations.

The goal of this analysis was to measure intrapopulation variability in carbon $\left(\delta^{13} \mathrm{C}\right)$ and nitrogen $\left(\delta^{15} \mathrm{~N}\right)$ SI values in a representative estuarine omnivore (Spotted Seatrout) to improve understanding and interpretation of SI data in an estuarine ecosystem in the northern Gulf of Mexico. The study objectives were 1) to quantify individual variation in carbon and nitrogen isotopic values of Spotted Seatrout in the laboratory and in wild populations; 2) to examine spatial and seasonal changes in the isotopic value of various tissue types with different turnover rates; and 3) to quantify intrapopulation variability for carbon and nitrogen isotopes in the laboratory and compare these estimates with field-based and literature reported values for isotope variability. A characterization of these sources of variability will allow for a clearer interpretation of how opportunistic changes in fish diet may be reflected in seasonal or spatial variances in isotope values.

\section{Methods}

Spotted Seatrout were collected from regular surveys conducted monthly by the University of Southern Mississippi Center for Fisheries Research and Development at 8 sites in coastal Mississippi (Fig. 1). Additional fish were also captured at 2 additional sites as part of a second survey of composition of fish communities associated with oyster reefs in the western Mississippi Sound (Fig. 1). Both surveys were conducted from 2007 to 2009. All fish were captured during 1-h sets of an experimental gillnet with 5 panels $(30.48 \times 1.83 \mathrm{~m}$ with mesh sizes of 50.8, 63.5, 76.2, 88.9, and $101.6 \mathrm{~mm}$ ). All Spotted Seatrout collected were identified based on taxonomic descriptions of Hoese and Moore (1977), measured to the nearest $1 \mathrm{~mm}$ (total length [TL]) and weighed to the nearest $1 \mathrm{~g}$ (wet weight), returned to the laboratory on ice, and immediately frozen at $-20^{\circ} \mathrm{C}$. In the laboratory, fish were thawed and tissue samples were collected: 2 samples of white muscle were collected from the left and right side of the fish dorsal to the midline, and 2 samples were collected of liver tissue. Both muscle and liver samples were freeze-dried to a constant weight, ground to a fine power, homogenized, and stored in a desiccator for stable isotope analysis.

Stable isotope ratios for $\delta^{13} \mathrm{C}$ and $\delta^{15} \mathrm{~N}$ were employed to delineate spatial and temporal changes in the SI values of individual fish within and between local populations. The high lipid content of liver tissue necessitated the need for a correction factor because lipids are typically depleted in ${ }^{13} \mathrm{C}$ relative to carbohydrates and protein (Deniro and Epstein, 1977). Ten liver samples were split into 2 parts; lipid was extracted from half the sample and the other half was unaltered. Each lipid subset of liver tissue samples was extracted sequentially with 2:1 chloroform:methanol and 1:2 chloroform:methanol mixtures, dried, and homogenized before analysis (Bligh and Dyer, 1959; Ruiz et al., 2007). The $\delta^{13} \mathrm{C}$ results of the lipid-extracted samples were plotted against the results of the nonextracted samples, and the resultant linear equation was used to correct the liver $\delta^{13} \mathrm{C}$ values for lipid content:

$$
\delta^{13} \mathrm{C}_{\text {extracted }}=\left(0.9975 \times \delta^{13} \mathrm{C}_{\text {nonextracted }}\right)+2.0578,(1)
$$

where the coefficient of determination $\left[r^{2}\right]=0.93$.

Samples were analyzed with a DELTA V Advantage ${ }^{1}$ stable isotope ratio mass spectrometer (Thermo Scientific, Waltham, MA) coupled to an ECS 4010 elemental combustion system (Costech Analytical Technologies, Inc., Valencia, CA). All samples were analyzed in duplicate and referenced to known isotopic standards and are reported in per mil notation (\%o). Nitrogen is referenced to atmospheric nitrogen and carbon to the Pee Dee Belemnite (PDB) standard.

The $\delta^{15} \mathrm{~N}$ value was used to calculate mean trophic level by site and month based on a general formula reported by Rooker et al. (2006):

$$
\text { Trophic level }=1.0+\left(\delta^{15} \mathrm{~N}-6.0\right) / 3.2,
$$

where 3.2 is the reported mean fractionation factor for nitrogen in fish (Peterson and Fry, 1987; Post, 2002) and 6.0 is the mean $\delta^{15} \mathrm{~N}$ value of primary producers in Gulf of Mexico coastal estuaries on the basis of both analysis of samples collected as part of separate projects in Mississippi Sound (senior author, unpubl. data)

\footnotetext{
${ }^{1}$ Mention of trade names or commercial companies is for identification purposes only and does not imply endorsement by the National Marine Fisheries Service, NOAA.
} 


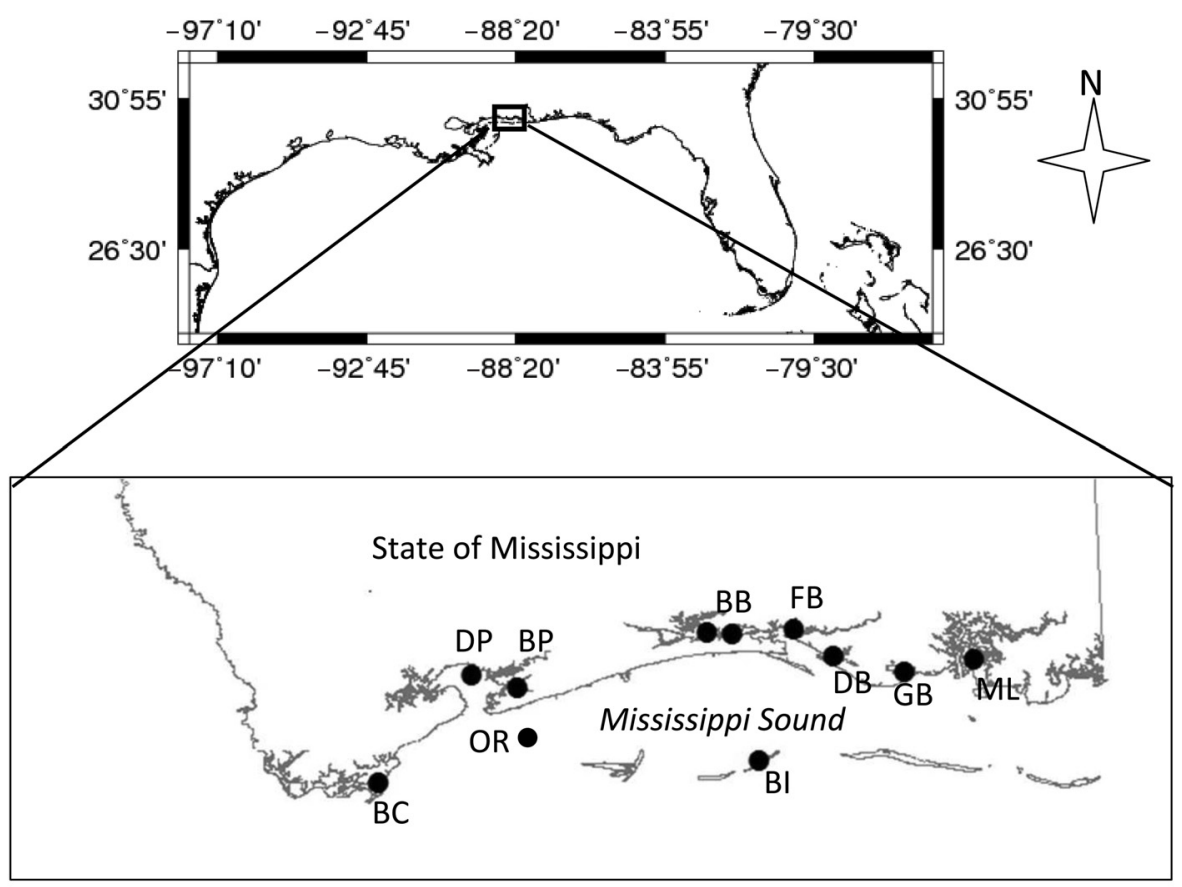

Figure 1

Map of 10 collection sites for Spotted Seatrout (Cynoscion nebulosus) captured in coastal Mississippi and the western Mississippi Sound during 2007-09 for this study of intrapopulation variability in stable isotope values for this species. Sites are labeled as Bayou Caddy (BC), Dupont (DP), Bayou Portage (BP), oyster reefs (OR), Back Bay (BB, 2 locations), Fort Bayou (FB), Davis Bayou (DB), Graveline Bayou (GB), Marsh Lake (ML), and Barrier Islands (BI). Fish were collected at random at the Barrier Island site, and therefore fish collected at the Barrier Islands may have been collected adjacent to either of the 2 largest of the Barrier Islands.

and similar values reported in the literature for the coastal Gulf of Mexico (Winemiller et al., 2007). Previously reported $\delta^{15} \mathrm{~N}$ values for primary producersneedlegrass rush (Juncus roemerianus Scheele), smooth cordgrass (Spartina alterniflora), and edaphic algaein a salt marsh within Graveline Bayou ranged from $5.2 \%$ to $6.1 \%$ (Sullivan and Moncreiff, 1990). Values for shoalweed (Halodule wrightii Asch.), associated epiphytes, and sand microflora from Horn Island were reported to range from $4.4 \%$ to $7.8 \%$, and various species of macroalgae from the same site had $\delta^{15} \mathrm{~N}$ values ranging from $4.7 \%$ to $10.0 \%$ (Moncreiff and Sullivan, 2001). Although much remains to be learned about nitrogen sources and variability within Mississippi Sound as one travels from the mainland to the Barrier islands, the average $\delta^{15} \mathrm{~N}$ value of 6.0 was considered a reasonable estimate on the basis of the data available. Intrapopulation variability of $\delta^{13} \mathrm{C}$ and $\delta^{15} \mathrm{~N}$ was calculated separately on the basis of a comparison of isotope ratios for hatchery-reared Spotted Seatrout $(n=20)$ fed with a single processed food. Fish used for variability estimates were kept under constant conditions of temperature and salinity and fed continually from a fixed food source for at least 6 months before analysis. This food source was a commercially available pellet food used successfully in the culture of Spotted Seatrout $\left(\right.$ Blaylock $\left.^{2}\right)$, and all feed used for this study was taken from a single lot to assure compositional consistency.

Stable isotope data were analyzed to quantify differences in both $\delta^{13} \mathrm{C}$ and $\delta^{15} \mathrm{~N}$ isotope values by location and sampling month with an analysis of variance (ANOVA). All post-hoc comparisons were conducted with a Tukey's honestly significant difference (HSD) test. The relationships between both $\delta^{13} \mathrm{C}$ and $\delta^{15} \mathrm{~N}$ isotope values and fish size also were fitted to a simple linear regression to test for the existence of a slope significantly greater than zero that would indicate a relationship between isotope enrichment and fish size. Both $\delta^{13} \mathrm{C}$ and $\delta^{15} \mathrm{~N}$ isotopes values in liver tissue were compared with results from white muscle and tested for deviation from a 1:1 relationship with a comparison of slopes ( $t$-test). All statistical tests were conducted with a type-I error rate of 0.05 .

\footnotetext{
${ }^{2}$ Blaylock, R. 2011. Personal commun. Thad Cochran Marine Aquaculture Center, Gulf Coast Research Laboratory, Univ. Southern Mississippi, 703 East Beach Road, Ocean Springs, MS 39564.
} 


\section{Table 1}

Summary of mean total length (TL, mm), sample size $(n)$, and mean carbon $\left(\delta^{13} \mathrm{C}\right)$ and nitrogen $\left(\delta^{15} \mathrm{~N}\right)$ stable isotope values (\%o) and their standard deviations (SD) by sample location for Spotted Seatrout (Cynoscion nebulosus) collected at 10 sites in coastal Mississippi and the western Mississippi Sound in 2007-09. Data for "reference" samples were obtained from laboratory-reared fish used to calculate intrinsic variability. Map code refers to site labels in Figure 1. The map code na (not available) indicates that the reference fish are not show in Figure 1.

\begin{tabular}{lccrcc}
\hline Location & Map code & $\begin{array}{c}\text { TL }[\mathrm{mm}] \\
\text { (SD) }\end{array}$ & $n$ & $\begin{array}{c}\text { Mean } \delta^{13} \mathrm{C} \\
\text { (SD) }\end{array}$ & $\begin{array}{c}\text { Mean } \delta^{15} \mathrm{~N} \\
\text { (SD) }\end{array}$ \\
\hline Bayou Caddy & BC & $323(61)$ & 30 & $-20.8(0.9)$ & $14.3(0.9)$ \\
Dupont & DP & $289(54)$ & 9 & $-21.9(1.8)$ & $13.7(1.2)$ \\
Bayou Portage & BP & $279(45)$ & 31 & $-22.6(1.3)$ & $13.5(0.8)$ \\
Oyster reefs & OR & $357(51)$ & 24 & $-21.7(1.1)$ & $14.3(0.6)$ \\
Back Bay & BB & $366(53)$ & 10 & $-22.1(1.9)$ & $14.8(0.6)$ \\
Fort Bayou & FB & $290(54)$ & 4 & $-21.0(1.3)$ & $14.7(1.0)$ \\
Davis Bayou & DB & $296(71)$ & 16 & $-21.3(1.4)$ & $13.1(1.1)$ \\
Graveline Bayou & GB & $271(47)$ & 15 & $-20.6(1.1)$ & $12.8(0.8)$ \\
Marsh Lake & ML & $439(40)$ & 2 & $-20.6(1.4)$ & $14.4(0.6)$ \\
Barrier Islands & BI & $500(76)$ & 33 & $-19.1(1.7)$ & $15.1(1.0)$ \\
Reference & na & $210(13)$ & 20 & $-18.03(0.24)$ & $12.74(0.2)$ \\
& & & & & \\
\hline
\end{tabular}

Finally, to assess the potential bias on sample variability with pooling fish for analysis of $\delta^{13} \mathrm{C}$ isotope values, a simple resampling numerical experiment was conducted on data from all site and date combinations that produced at least 30 fish for analysis. Subsamples that consisted of between 2 and 20 randomly selected fish were averaged to produce a "pooled" value for $\delta^{13} \mathrm{C}$, and means of pooled data were calculated from each pooled subsample ( $n=10$ subsamples selected with replacement) for each resampled size. These data were then plotted to assess bias in the result by comparison of the resampled mean with the nonpooled sample mean for each set of data. The pattern in the absolute residuals was examined as a function of resample size to estimate minimum effective pooled sample size for each data set.

\section{Results}

From 10 sites over the period of 2007-09, 187 individual Spotted Seatrout were captured (Fig. 1, Table 1). All fish were captured between May and October and sampling coverage was relatively even across months with the exception of September, which yielded only 3 fish. Fish ranged in size from 212 to $622 \mathrm{~mm}$ TL, but mean TL by site was $250-350 \mathrm{~mm}$ TL with the exception of fish collected near the Barrier Islands. The mean $\delta^{13} \mathrm{C}$ for all fish across all sites was $-21.4 \%$ (standard deviation [SD] of 1.6\%o.) The system-wide standard deviation was generally similar to the within-site standard deviation but close to the within-site maximum (Table 1 ). The mean $\delta^{15} \mathrm{~N}$ across all sites was $13.9 \%$ (SD of $1.1 \%$ ). As with $\delta^{13} \mathrm{C}$, the overall standard deviation was within the range of within-site variability but toward the high end of the range. On the basis of the $\delta^{15} \mathrm{~N}$ data, Spotted Seatrout collected from field sites feed at a mean trophic level of 3.4. The standard deviation of both $\delta^{13} \mathrm{C}$ and $\delta^{15} \mathrm{~N}$ for reference fish raised in the laboratory was $<20 \%$ of field-based estimates of withinsample variability (Table 1 ).

The $\delta^{13} \mathrm{C}$ and $\delta^{15} \mathrm{~N}$ isotope ratios of Spotted Seatrout showed an inshore-to-offshore and summer-tofall enrichment trend. Both $\delta^{13} \mathrm{C}$ and $\delta^{15} \mathrm{~N}$ values examined showed a statistically significant trend across sites $\left(\delta^{13} \mathrm{C}\right.$ ANOVA, $F_{9,161}=2.61, P=0.008 ; \delta^{15} \mathrm{~N}$ $\left.F_{9,161}=3.44, P<0.0001\right)$ and sample months $\left(\delta^{13} \mathrm{C}\right.$ ANO$\left.\mathrm{VA}, F_{5,161}=7.35, P<0.0001 ; \delta^{15} \mathrm{~N} F_{5,161}=9.29, P<0.0001\right)$. Post-hoc analysis indicated a significant difference between fish collected at inland, marsh-associated sites, such as Graveline Bayou, Davis Bayou, Bayou Portage, and Dupont, and fish captured near the Barrier Islands (Fig. 2A). Isotope values overlapped considerably among more open-water sites in Mississippi Sound (Bayou Caddy and oyster reefs), Marsh Lake, and Back Bay at both marsh-associated sites and Barrier Islands sites, but the open-water sites were closer than the Barrier Islands sites in isotopic value to marsh-associated sites. In terms of months, June, July, and August were statistically different from October, but this difference was confounded with site differences because most fish captured in October were from around the Barrier Islands (Fig. 2B). There was also a small but significant positive linear trend in both $\delta^{13} \mathrm{C}$ and $\delta^{15} \mathrm{~N}$ with fish TL (Fig. 3).

The lipid-corrected stable isotope values of Spotted Seatrout liver samples were similar to results from white muscle for both $\delta^{13} \mathrm{C}$ and $\delta^{15} \mathrm{~N}$ but contained no- 


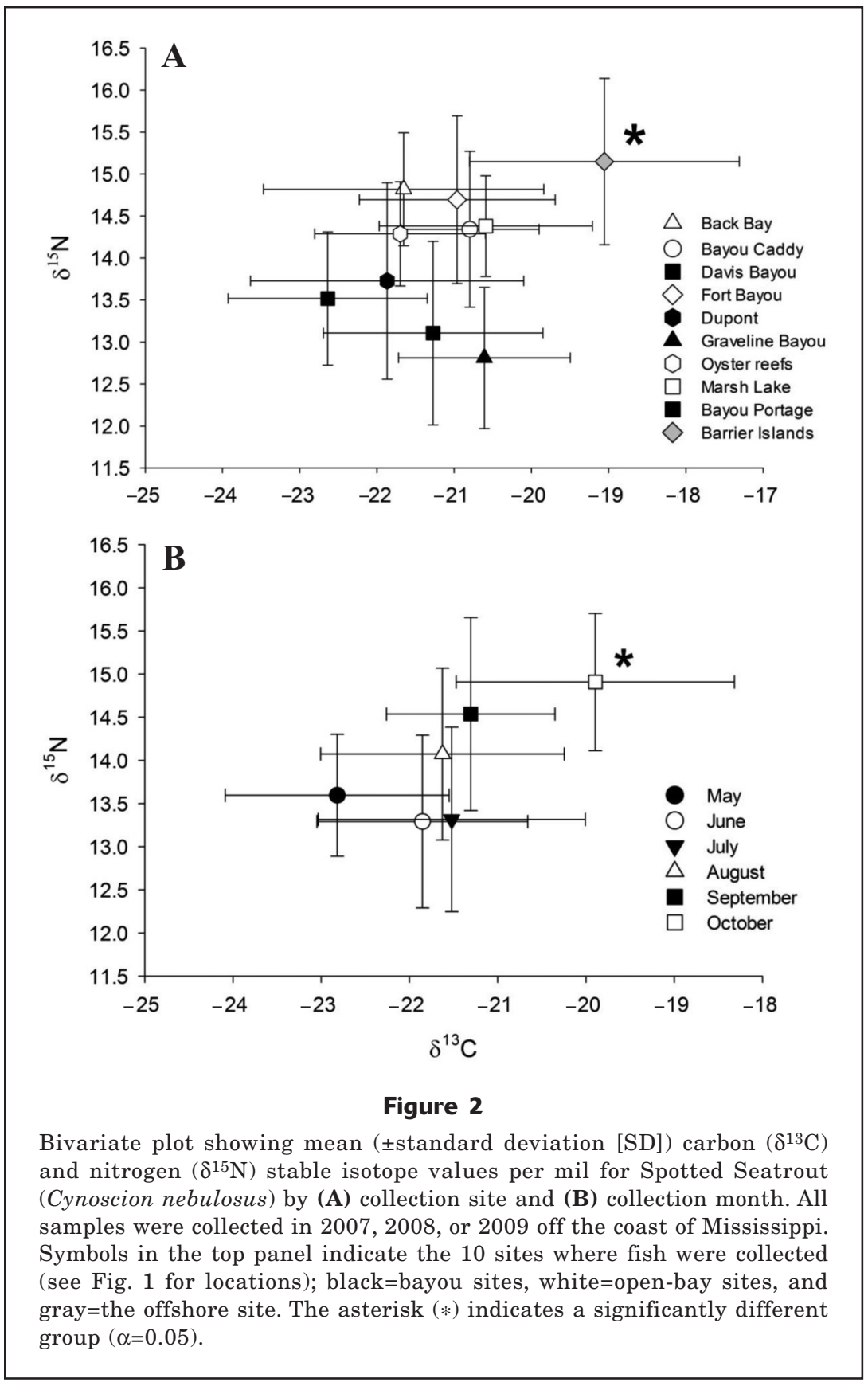

ticeable bias. The relationship between lipid-corrected $\delta^{13} \mathrm{C}$ data from liver samples and data for muscle displayed a relationship significantly different from $1: 1$ ( $t$-test, slope=0.25, $P<0.001$; Fig. 4A) with a shift from positive to negative bias in liver $\delta^{13} \mathrm{C}$ values as muscle $\delta^{13} \mathrm{C}$ values increased. However, although $\delta^{15} \mathrm{~N}$ values also showed a linear trend between liver and muscle samples with a slope that differed significantly from one $\left(\delta^{15} \mathrm{~N}\right.$ slope $\left.=0.50, P<0.001\right)$, liver tissue showed more consistent depletion bias than muscle tissue (Fig. $4 \mathrm{~B})$. This bias increased with overall enrichment of $\delta^{15} \mathrm{~N}$ in muscle tissue.
The resampling procedure was performed on data from 3 sites: Bayou Portage, Bayou Caddy, and the Barrier Islands. These sites had the largest sample sizes and showed some contrast between nearshore and open-water sites. Intersample variability was related to pooled resample size ( $n$; Fig. 5 ). A high mean absolute residual value ( $>0.1$ ) was observed for $n \leq 3$ but dropped rapidly to a value $<0.05$ for an $n>5$. This pattern was consistent across sites despite a large difference in residual values at smaller pooled resample sizes. In general, bias in mean isotopic ratio was minimal at any pooled resample size greater than $n=5$. 

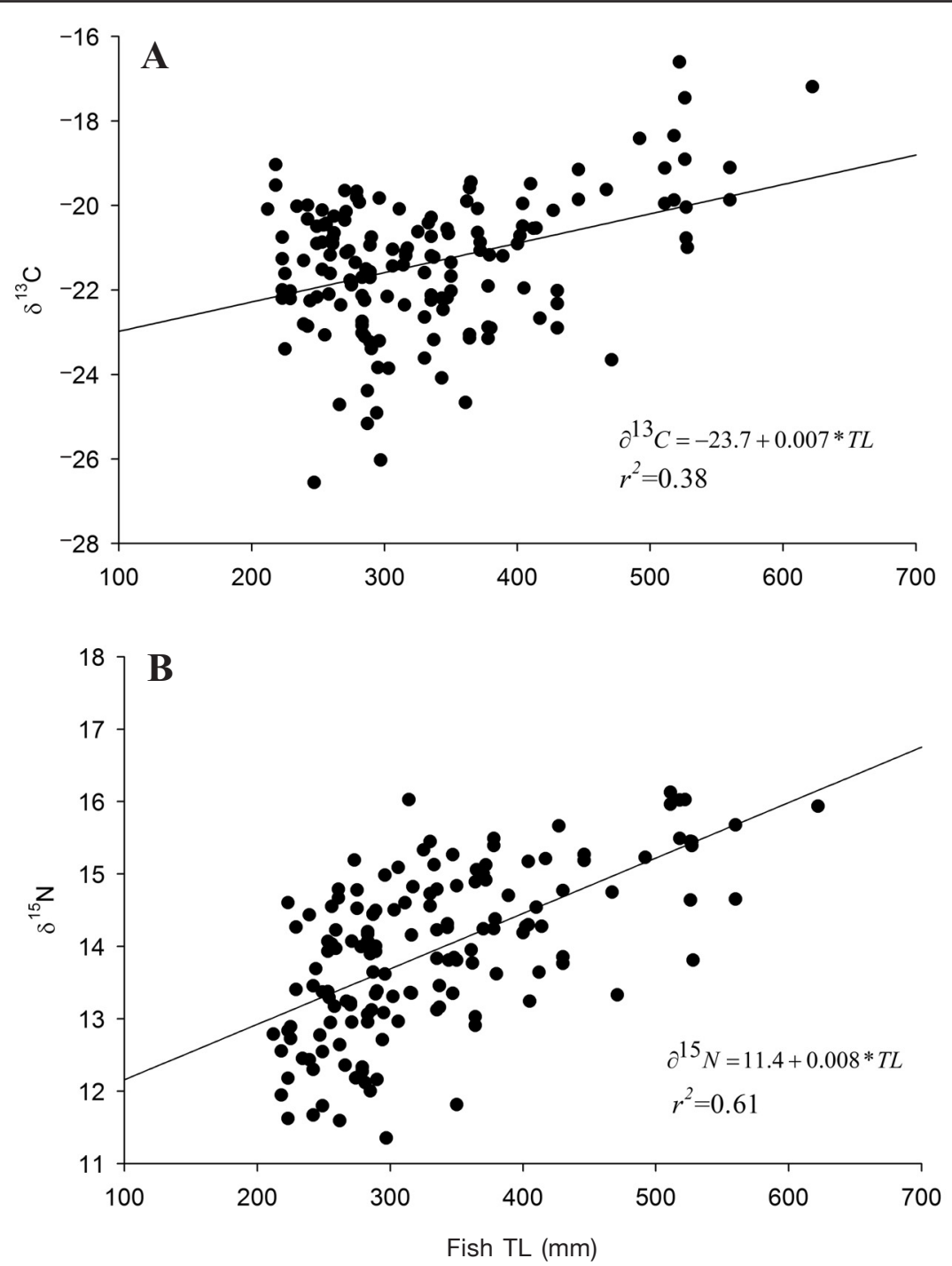

Figure 3

Scatter plot of fish total length (TL, mm) against (A) carbon $\left(\delta^{13} \mathrm{C}\right)$ and (B) nitrogen $\left(\delta^{15} \mathrm{~N}\right)$ stable isotope values per mil for Spotted Seatrout (Cynoscion nebulosus) examined in this study. The solid line on each panel indicates the best-fit regression line for each data set. $r^{2}=$ coefficient of determination.

\section{Discussion}

Effects of tissue type, fractionation, and fish size

Both $\delta^{13} \mathrm{C}$ and $\delta^{15} \mathrm{~N}$ SI values can differ between tissue types (Pinnegar and Polunin, 1999). Differences between the isotopic values of fish liver and muscle tissue have been ascribed to differences in tissue turnover rates of liver and muscle (Sweeting et al., 2005), and to seasonal differences in growth rates, feeding behavior, and prey availability (Perga and Gerdeaux, 2005). However, in subtropical waters, such as Missis- sippi Sound, fish growth likely occurs throughout the year (Vetter, 1982), and, in this study, $\delta^{13} \mathrm{C}$ values of liver and muscle were generally very similar, indicating that the pattern reported by Perga and Gerdaeux (2005) at more northern latitudes was not observed in this study. The isotopic values for $\delta^{15} \mathrm{~N}$ did show a negative bias in liver compared with muscle. Because all sampling occurred during periods of probable high growth (summer and fall), this result may be related to differences in isotopic fractionation and turnover rates between tissue types.

The increase in both $\delta^{13} \mathrm{C}$ and $\delta^{15} \mathrm{~N}$ with fish size 

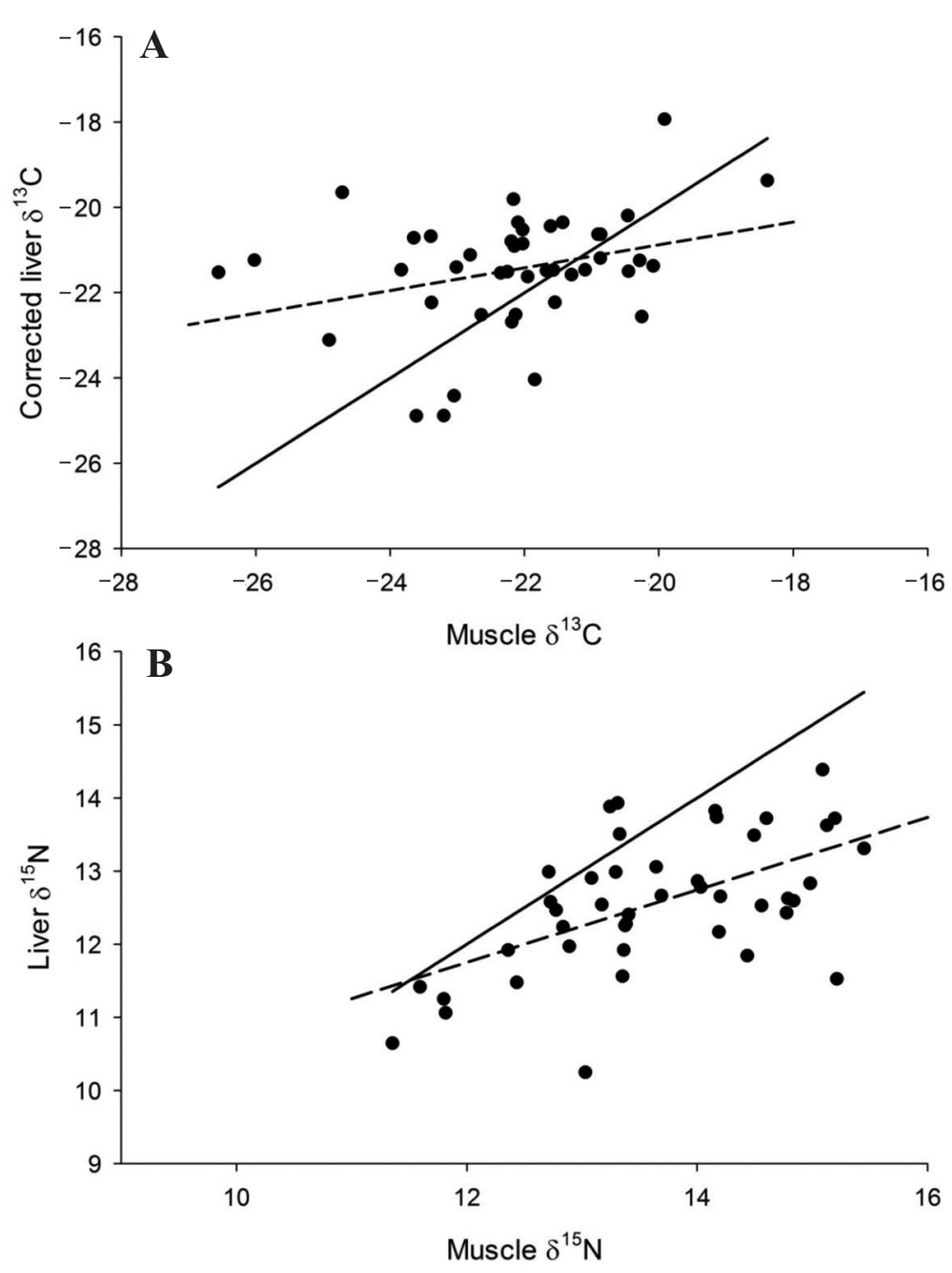

Figure 4

Scatter plot of $(\mathbf{A})$ carbon $\left(\delta^{13} \mathrm{C}\right)$ and $(\mathbf{B})$ nitrogen $\left(\delta^{15} \mathrm{~N}\right)$ stable isotope values per mil for liver and muscle tissue from Spotted Seatrout (Cynoscion nebulosus) examined in this study. Data for $\delta^{13} \mathrm{C}$ in liver tissue are corrected for lipid content on the basis of a derived empirical relationship. See Methods section for details. The solid lines on each panel describe a 1:1 relationship, and dashed lines are the best fit linear regressions for $\delta^{13} \mathrm{C}$ $(y=0.25 x-15.4)$ and $\delta^{15} \mathrm{~N}(y=0.50 x+5.2)$ respectively.

was small but significant and generally supports an increase in trophic level as fish grow and move offshore. The increase in $\delta^{15} \mathrm{~N}$ observed over the size range of fish in our study was close to $3 \%$, nearly a full trophic level. The size range of fish in this study was relatively wide but probably includes only fish beyond their first year-an assumption made on the basis of published growth curves (Fulford and Hendon, 2010). The probable age range of these fish suggests that an ontogenetic diet shift associated with maturation is dif- ficult to extrapolate from these data because the trend of increasing heavy isotope values is confounded by changes in prey availability, by increases in fish prey capture efficiency with seatrout size, and by the potential variability of carbon and nitrogen sources within the Mississippi Sound and its subestuaries. The largest Spotted Seatrout were caught in open water, mainly offshore near the Barrier Islands, where prey fishes of higher trophic level, such as anchovies (e.g., Striped Anchovy [Anchoa hepsetus]) that have a mean trophic 


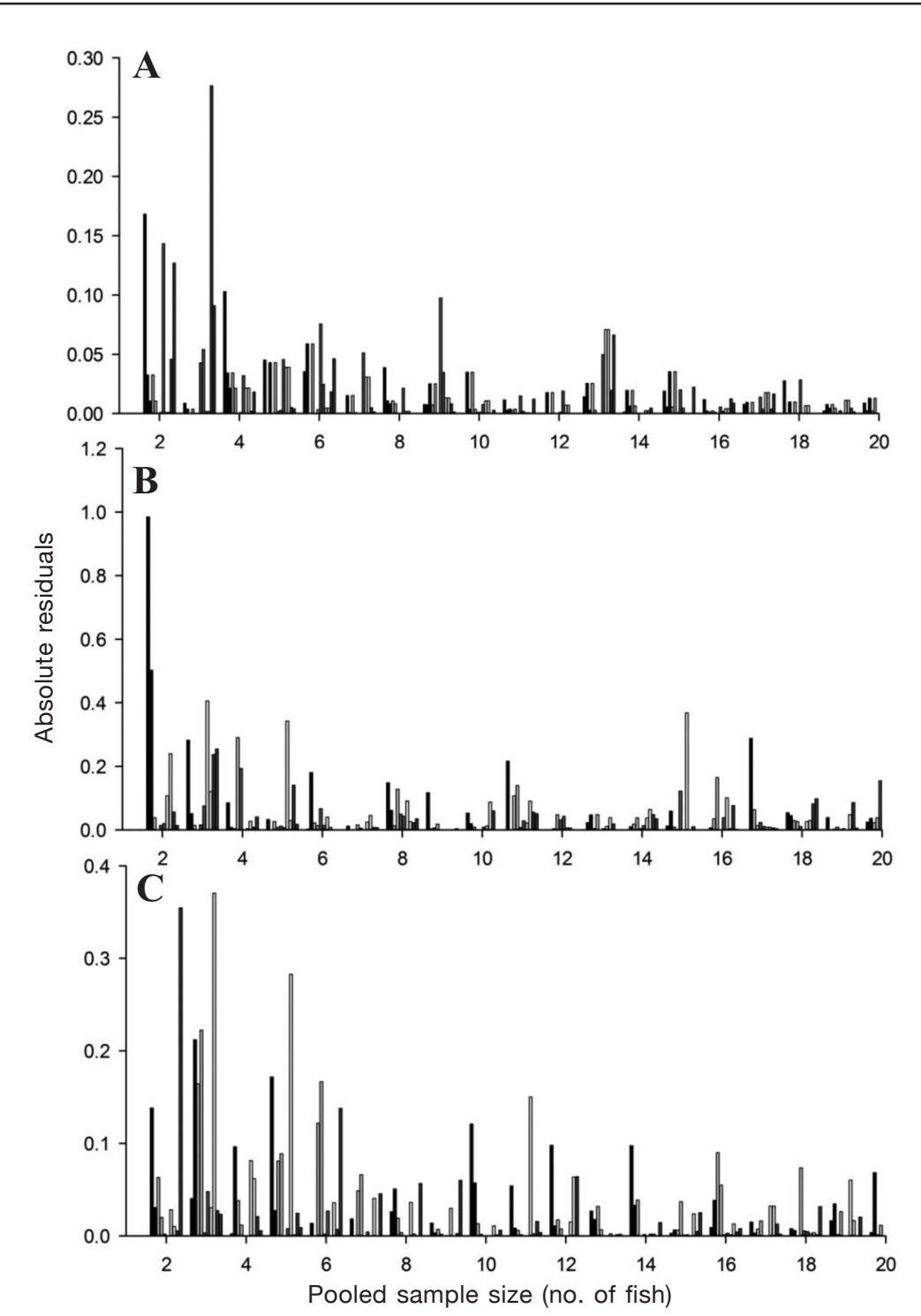

Figure 5

Bar plot summarizing the absolute residuals of resampled set means from the overall site means of carbon $\left(\delta^{13} \mathrm{C}\right)$ stable isotope values per mil for simulated pooling of data from 3 sites: (A) Bayou Caddy, (B) Barrier Islands, and (C) Bayou Portage. Random resampling was used to simulate pooling between 2 and 20 fish into a single resampled set. Each bar represents the residual for a set, and there are 10 sets for each resampling size.

level similar to that of Spotted Seatrout captured at inshore sites, may be more prevalent.

\section{Spatial and temporal differences in SI}

Spatial and temporal patterns in SI composition were interrelated and consistent with a seasonal offshore movement of individual fish (Hendon et al., 2002). Overall, across all sites, mean $\delta^{13} \mathrm{C}$ for Spotted Seatrout in coastal Mississippi suggests a stronger influence of pelagic primary production than of terrestrial sources on the diet of Spotted Seatrout. Yet, there was a detectable trend: the least-enriched samples were collected in nearshore waters in small embayments, and the mostenriched samples were collected farther offshore near the Barrier Islands. A clear inshore-to-offshore pattern of enrichments was also displayed by $\delta^{15} \mathrm{~N}$ SI values, a finding that is consistent with increases in trophic 
level as fish begin to migrate offshore, although spatial variability in $\delta^{15} \mathrm{~N}$ may also contribute to the observed differences. There was much overlap between sites, but the separation of small embayments from the Barrier Islands was detectable in both carbon and nitrogen, and therefore the seasonal-spatial pattern seems robust for within-site variability and occurs at a temporal scale larger than that for the tissue isotopic turnover rate.

These results also are consistent with isotopic values of Spotted Seatrout in Graveline Bayou reported by Sullivan and Moncreiff (1990), who found that Spotted Seatrout had a mean $\delta^{13} \mathrm{C}$ value of -20.7 and a mean $\delta^{15} \mathrm{~N}$ ratio of 11.8 -results that are very similar to the values reported here for Spotted Seatrout caught in Graveline Bayou. Our data, however, also indicate that these values are the middle of the overall range for $\delta^{13} \mathrm{C}$ and near the bottom of the range for $\delta^{15} \mathrm{~N}$ across all sites in Mississippi. A more comprehensive analysis of Spotted Seatrout position in the coastal food web will require sampling over a broad spatial and temporal scale. Still, ecological patterns, such as spatial and temporal differences in SI values, are detectable, and therefore stable isotope data can be used for understanding trophic relationships in this species.

Individual variability in SI composition within a population can confound ecological patterns particularly for omnivores (Quevedo et al., 2009; Sweeting et al., 2005). Population variability can be caused by individual physiological differences (i.e., differences in isotopic fractionation or growth and tissue turnover rates); individual differences in behavior, prey availability or prey preference; and changes in environmental conditions that may influence individual movement, metabolism, growth, and diet (Barnes et al., 2008). Our analysis shows that individual variability measured in the laboratory with a diet of a single commercial feed is quite low (standard deviation $=0.24$ ) in comparison with that derived from field studies (median standard deviation=1.5), showing that ecologically relevant isotopic variability in Spotted Seatrout is detectable in field populations.

Detection of population-level differences through space and time can be confounded by this individual variability within population-level samples. Pooling of individuals into a common sample for analysis is, therefore, an often used method for reduction of individual variability to increase the focus on populationlevel questions. How much pooling is enough to reduce individual variation? Our resampling experiment indicates that the effectiveness of pooling is maximized for a subsample size of 5-6 individual fish. Smaller subsamples introduced potential bias due to individual variation, and larger subsamples reduced sampling efficiency. In general, we advocate pooling only for investigations of interpopulation differences or for changes in a single population through time. Individual variability has been found to be important in detection of behavior patterns (Sweeting et al., 2005) and in com- munity-level studies (Bolnick et al., 2003; Matthews and Mazumder, 2004).

\section{Conclusions}

Understanding the trophic role of omnivores, such as Spotted Seatrout, is a critical part of estuarine ecosystem-based management, and SI analysis is a valuable tool for trophic studies of this species. Diet data are needed for identification of important prey species, but such data can be biased by small sample sizes and do not provide information on differences in total assimilation across prey species. Stable isotope analysis is an important complementary tool that allows the characterization of trophic pathways at broader spatial and temporal scales. However, variability in SI values within a population can be caused by factors unrelated to diet shifts, and these mitigating factors must be accounted for and incorporated into trophic studies to achieve meaningful results.

Our findings substantiate the utility of stable isotope analysis for quantification of the trophic role of Spotted Seatrout in an estuarine system and demonstrate that this trophic role changes spatially and temporally in predictable ways that can be incorporated into ecosystem studies. The trophic role of Spotted Seatrout is not static, it is dependent on factors, such as habitat, life stage, and fish size that are not independent of one another. Spotted Seatrout are known to display minimal movement before sexual maturation (Hendon et al., 2002), and this behavior indicates that the observed patterns in trophic role are related more to alterations in migration patterns as fish grow rather than to opportunistic movement not related to ontogeny. Such distinctions are important for understanding the role of a fish population within an ecosystem, and this research will directly benefit the more comprehensive study that is needed to understand the impact of habitat on Spotted Seatrout production. More broadly, patterns in both intra- and interpopulation variability in SI values need to be well understood for SI analysis to provide an unbiased measure of trophic connectivity within estuarine ecosystems. Studies such as this one that explicitly measure these variables in a target ecosystem are extremely valuable for the application of SI data to ecosystem management.

\section{Acknowledgments}

This study was made possible with the time and efforts of personnel at the University of Southern Mississippi Center for Fisheries Research and Development. We thank W. Dempster and J. Dietrich for their help in collecting fish and E. Myers and C. Messer for their help in processing samples for analysis. This project was funded by a grant from the Mississippi-Alabama Sea Grant Consortium and the Northern Gulf Institute. 
The research described in this article was developed by the author, an employee of the U.S. Environmental Protection Agency (EPA), on his own time. This research was conducted independent of EPA employment, and has not been subjected to the Agency's peer and administrative review. Therefore, the conclusions and opinions drawn are solely those of the author and are not necessarily the views of the EPA.

\section{Literature cited}

Arkema, K. K., S. C. Abramson, and B. M. Dewsbury.

2006. Marine ecosystem-based management: from characterization to implementation. Front. Ecol. Environ. 10:525-532.

Barnes, C., S. Jennings, N. V. C. Polunin, and J. E. Lancaster. 2008. The importance of quantifying inherent variability when interpreting stable isotope field data. Oecologia 155:227-235.

Bligh, E. G., and W. J. Dyer.

1959. A rapid method of total lipid extraction and purification. Can. J. Biochem. Physiol. 37:911-917.

Bolnick, D. I., R. Svanbäck, J. A. Fordyce, L. H. Yang, J. M. Davis, C. D. Hulsey, and M. L. Forister.

2003. The ecology of individuals: incidence and implications of individual specialization. Am. Nat. 161:1-28.

Brodziak, J., and J. Link.

2002. Ecosystem-based fishery management: what is it and how can we do it? Bull. Mar. Sci. 70:589-611.

Christensen, N. L., A. M. Bartuska, J. H. Brown, S. R. Carpenter, C. D'Antonio, R. C. Francis, J. F. Franklin, J. A. MacMahon, R. F. Noss, D. J. Parsons, C. H. Peterson, M. G. Turner, and R. G. Woodmansee.

1996. The report of the Ecological Society of America committee on the scientific basis for ecosystem management. Ecol. Appl. 6:665-691.

Christensen, V., and D. Pauly.

2004. Placing fisheries in their ecosystem context, an introduction. Ecol. Model. 172:103-107.

Dame, J. K., and R. R. Christian.

2006. Uncertainty and the use of network analysis for ecosystem-based management. Fisheries 31:331-341.

Deniro, M. J., and S. Epstein.

1977. Mechanism for carbon isotope fractionation associated with lipid synthesis. Science 197:261-263.

Fulford, R. S., and J. R. Hendon.

2010. Evaluating management actions for spotted seatrout, Cynoscion nebulosus, in Mississippi with an age-structured projection model. Gulf Caribb. Res. 22:51-61.

Hendon, J. R., J. R. Warren, J. S. Franks, and M. V. Buchanan. 2002. Movements of spotted seatrout (Cynoscion nebulosus) in Mississippi coastal waters based on tag-recapture. Gulf Mex. Sci. 20:91-97.

Herzka, S. Z.

2005. Assessing connectivity of estuarine fishes based on stable isotope ratio analysis. Estuar. Coast. Shelf Sci. 64:58-69.

Hoese, H. D., and R. H. Moore.

1977. Fishes of the Gulf of Mexico: Texas, Louisiana, and adjacent waters, 327 p. Texas A\&M Univ. Press, College Station, TX.
Matthews, B., and A. Mazumder.

2004. A critical evaluation of intrapopulation variation of $\delta^{13} \mathrm{C}$ and isotopic evidence of individual specialization. Oecologia 140:361-371.

Moncreiff, C. A., and M. J. Sullivan.

2001. Trophic importance of epiphytic algae in subtropical seagrass beds: evidence from multiple stable isotope analyses. Mar. Ecol. Prog. Ser. 215:93-106.

NRC (National Research Council).

1999. Sustaining marine fisheries, 184 p. National Academy Press, Washington, D.C.

Perga, M. E., and D. Gerdeaux.

2005. 'Are fish what they eat' all year round? Oecologia 144:598-606.

Peterson, B. J., and B. Fry.

1987. Stable isotopes in ecosystem studies. Annu. Rev. Ecol. Sys. 18:293-320.

Pinnegar, J. K., and N. V. C. Polunin.

1999. Differential fractionation of $\delta^{13} \mathrm{C}$ and $\delta^{15} \mathrm{~N}$ among fish tissues: implications for the study of trophic interactions. Funct. Ecol. 13:225-231.

Post, D. M.

2002. Using stable isotopes to estimate trophic position: models, methods, and assumptions. Ecology 83:703-718.

Power, M., G. Power, F. Caron, R. R. Doucett, and K. R. A. Guiguer.

2002. Growth and dietary niche in Salvelinus alpinus and Salvelinus fontinalis as revealed by stable isotope analysis. Environ. Biol. Fishes 64:75-85.

Quan, W., C. Fu, B. Jin, Y. Luo, B. Li, J. Chen, and J. Wu.

2007. Tidal marshes as energy sources for commercially important nektonic organisms: stable isotope analysis. Mar. Ecol. Prog. Ser. 352:89-99.

Quevedo, M., R. Svanbäck, and P. Eklöav.

2009. Intrapopulation niche partitioning in a generalist predator limits food web connectivity. Ecology 90:2263-2274.

Rooker, J. R., J. P. Turner, and S. A. Holt.

2006. Trophic ecology of Sargassum-associated fishes in the Gulf of Mexico determined from stable isotope analysis. Mar. Ecol. Prog. Ser. 313:249-259.

Ruiz, N., N. Dubois, G. Wielgosz-Collin, T. R. duPont, J. P. Berge, Y. F. Pouchus, and G. Barnathan.

2007. Lipid content and fatty acid composition of a marine-derived Trichoderma longibrachiatum strain cultured by agar surface and submerged fermentation. Process Biochem. 42:676-680.

Sullivan, M. J., and C. A. Moncreiff.

1990. Edaphic algae are an important component of salt marsh food-webs: evidence from a multiple stable isotope analysis. Mar. Ecol. Prog. Ser. 62:149-159.

Sweeting, C. J., S. Jennings, and N. V. C. Polunin.

2005. Variance in isotopic signatures as a descriptor of tissue turnover and degree of omnivory. Funct. Ecol. 19:777-784.

Thomas, J. W., and S. Huke.

1996. The Forest Service approach to healthy ecosystems. J. Forest. 94(8):14-18.

Vetter, R. D.

1982. Seasonal metabolic compensation in sympatric seatrout: adaptation to the estuary. Trans. Am. Fish. Soc. 111:193-198. 
Winemiller, K. O., S. Akin, and S. C. Zeug.

2007. Production sources and food web structure of a temperate tidal estuary: integration of dietary and stable isotope data. Mar. Ecol. Prog. Ser. 343:63-76.
Zanden, H. B. V., K. A. Bjorndal, K. J. Reich, and A. B. Bolten. 2010. Individual specialists in a generalist population: results from a long-term stable isotope series. Biol. Lett. 6:711-714. 